\title{
Assessing the influence of recollection and familiarity in memory for own- versus other-race faces
}

\author{
Jessica L. Marcon, Kyle J. Susa, and Christian A. Meissner \\ University of Texas, El Paso, Texas
}

\begin{abstract}
In the present research, we examined the contributions of recollection and familiarity in memory for own- and other-race faces. In Experiment 1, we used a repetition lag paradigm (Jennings \& Jacoby, 1997) to demonstrate the typical cross-race effect with respect to discrimination accuracy and response bias. Participants were more likely to commit repetition errors by falsely recognizing repeated other-race faces. In Experiment 2, we used process-dissociation equations to estimate differences in recollection and familiarity. As predicted, results showed a greater reliance on recollection-based processing for own-race faces. The theoretical and practical implications of these findings are discussed.
\end{abstract}

The cross-race effect (CRE) is the robust finding that memory for faces of one's own race is superior to memory for faces of another, less familiar race. Malpass and Kravitz (1969) first demonstrated the effect in recognition memory for white and black faces, and since then it has been demonstrated in numerous publications to be a robust and practically important phenomenon (for a recent metaanalytic review, see Meissner \& Brigham, 2001). A number of social-cognitive theories have been proposed to account for the CRE in face recognition (see Meissner \& Brigham, 2001; Sporer, 2001). Some researchers have proposed that interracial contact may account for differences in memory for own- and other-race faces (Brigham \& Malpass, 1985; Wright, Boyd, \& Tredoux, 2003). Although several studies have shown that individuals' geographic location (and their related degree of racial mixture) can predict performance on own- versus other-race faces (cf. Chiroro, Tredoux, Radaelli, \& Meissner, 2008; Chiroro \& Valentine, 1995), self-report measures of interracial contact have shown only small effects (see Meissner \& Brigham, 2001). Other researchers have proposed that differences in categorization processes may be at play, whereby other-race faces are categorized quickly at the expense of encoding individuating information (Levin, 1996, 2000; MacLin \& Malpass, 2001). Still others (Sporer, 2001; Valentine, 1991, 2001) have argued that the CRE may lie in differing representational structures to the extent that own-race faces are more appropriately encoded and represented by diagnostic feature classifications. These representational differences may arise as a function of differing encoding strategies, such as configural or featural processing (Rhodes, Tan, Brake, \& Taylor, 1989), although it has been suggested in recent studies that own-race faces may be processed to a greater extent using both configural and componential details (see Rhodes, Hayward, \& Winkler, 2006).

Recently, Meissner, Brigham, and Butz (2005) sought to apply dual-process theory to distinguish these various explanations of the effect. In dual-process theories, recognition memory is composed of two independent memory systems - namely, recollection and familiarity (Jacoby, 1991; Tulving, 1985; for a review, see Yonelinas, 2002). Recollection generally reflects a controlled, effortful process in which one is able to recall specific details about a memorial episode. Familiarity, in contrast, is a more fluid, automatic process characterized by a feeling of familiarity without any specific recollection. A variety of paradigms have been developed in order to assess these two processes, including process-dissociation tasks (Jacoby, 1991; Kelley \& Jacoby, 2000), receiver-operating characteristic analysis (Yonelinas, 1994, 1999), and remember-know-guess judgments (Gardiner \& Richardson-Klavehn, 2000).

Given previous research suggesting that effortful encoding, divided attention, and distinctiveness manipulations influence recollection but not familiarity (see Yonelinas, 2002), Meissner, Brigham, and Butz (2005) predicted that an encoding or representational basis for the CRE would result in a recollection advantage for ownrace faces. Such a prediction is supported by research indicating that the CRE is sensitive to variation in facial distinctiveness (Chiroro \& Valentine, 1995; Sporer, 2001; Valentine, 1991, 2001), as well as to the influence of racial categorization in diverting attentional resources from successful encoding (Levin, 1996, 2000; MacLin \& Malpass, 2001). In contrast, differences in familiarity might result if the CRE is due to stereotyping of other-race faces, if own-race faces are processed in a configural manner, or

C. A. Meissner, cmeissner@utep.edu 
if a shift in criterion is responsible for the effect. For example, it has been suggested that stereotyping responses tend to be rather automatic (Dasgupta, McGhee, Greenwald, \& Banaji, 2000) and are thus supported by an "accessibility bias" that is under limited conscious control (Payne, Lambert, \& Jacoby, 2002). As such, other-race faces may involve a greater familiarity response at the time of recognition. With regard to configural processing (or the representation of associations between internal facial features), Yonelinas, Kroll, Dobbins, and Soltani (1999) found that inversion effects appear to be isolated to familiarity-based processing. If configural processing is influenced by inversion and is dominant in own-race face recognition (Rhodes et al., 1989), we might expect greater familiarity-based processing to occur for own-race faces. Finally, it is worth noting that shifts in response criterion are generally captured by differences in familiarity-based responding (Yonelinas, 2001). If a more liberal response bias is chiefly responsible for the CRE (see Sporer, 2001), we might expect greater estimates of familiarity to be associated with responses to other-race faces.

Using a dual-process framework, Meissner, Brigham, and Butz (2005) asked participants to complete a standard recognition paradigm involving the presentation of both own- and other-race faces, and to provide rememberknow-guess judgments at the time of recognition. In this paradigm, when participants responded that they recognized a face from the study list, they were also asked to provide a judgment of either remember (they can recollect details of the study episode), know (they cannot recollect specific details, but report a general feeling of familiarity), or guess (they have no memory or experience of familiarity and are simply guessing). Meissner, Brigham, and Butz's results suggested that remember judgments (or recollection-based processing) were significantly greater in number when discriminating own-race faces (compared with when discriminating other-race faces), whereas no differences in know (corrected for independence) or guess judgments were observed. Meissner, Brigham, and Butz interpreted these findings to support those theories that argued that attentional, encoding, and representational differences lead to the CRE.

One potential criticism lodged against the rememberknow-guess procedure is that these judgments may not, in fact, index recollection and familiarity, but that they are, rather, indicators of confidence (Dunn, 2004). Additionally, feelings of remembering and knowing may not necessarily be indices of separable memory categories, such as recollection and familiarity in the dual-process memory literature, but instead may be the result of stimulus construction, context, experimental task, expectations regarding performance, or other aspects of the experience that the participants deem relevant (e.g., Bodner \& Lindsay, 2003). Given the various concerns expressed, the goal of the present research was to replicate previous research findings regarding the role of recollection in own- versus other-race face recognition using an alternative, processdissociation paradigm.

Our search for an appropriate process-dissociation paradigm led us to the work of Jennings and Jacoby
(1997). In their "repetition lag paradigm," young and old participants were presented a series of items at encoding that they would be subsequently asked to recognize from among a set of novel items. However, at recognition, the experimenters also repeated novel items at varying lags (or intervals), and participants were instructed to appropriately recognize these repeated items as distinct from those they had viewed at study. This repetition of novel items at test placed recollection and familiarity in opposition. Specifically, Jennings and Jacoby argued that the successful recognition of these repeated items as new required recollection of their prior presentation on the test list (as opposed to on the study list), whereas a failure of recollection and a reliance upon perceived familiarity would lead to a misattribution of old. Using this paradigm, Jennings and Jacoby showed that older adults were more likely to commit a repetition error, replicating prior studies suggesting that the ability to recollect is reduced as we age.

In a second experiment, Jennings and Jacoby (1997) refined the procedure to allow for the use of processdissociation equations to directly estimate recollection and familiarity. More specifically, participants were instructed to either exclude (say "no") or include (say "yes") repeated novel items at test. Although participants could respond yes to an inclusion trial on the basis of both recollection and familiarity (facilitation condition), exclusion trials were designed to place recollection and familiarity in opposition (opposition condition). Specifically, responding no to an exclusion trial required that participants be able to recollect the prior presentation of the face, whereas a yes response would likely be a product of context-free familiarity. Using this opposition procedure, Jennings and Jacoby were able to compute recollection and familiarity via process-dissociation equations (see Jacoby, 1991). Once again, their results confirmed differences in recollectionbased processing as a function of age, but they found no effect of familiarity.

In the present experiments, we sought to apply the Jennings and Jacoby (1997) framework to examine differences in recollection and familiarity in the recognition of own- and other-race faces. In Experiment 1, we assessed the extent to which participants commit repetition errors to a greater degree when recognizing other-race faces, whereas in Experiment 2, we more directly estimated the contributions of recollection and familiarity using process-dissociation equations. Consistent with prior research by Meissner, Brigham, and Butz (2005), it was predicted that participants would demonstrate repetition errors to a greater extent with other-race faces and that a failure of recollection would be responsible for the differences in processing own- and other-race faces.

\section{EXPERIMENT 1}

\section{Method}

Participants. Fifty-four Hispanic students (58\% female, mean age $=19.24$ years) from the University of Texas at El Paso participated in this experiment.

Materials. The facial stimuli used in this study included 25 Hispanic males and 25 African-American males. Two different photo- 
Table 1

Means and Standard Deviations of Hits, False Alarms,

Discrimination Accuracy $\left(A_{z}\right)$, Response Criterion $(C)$, and

Repetition Errors Across Own- and Other-Race Faces in Experiment 1

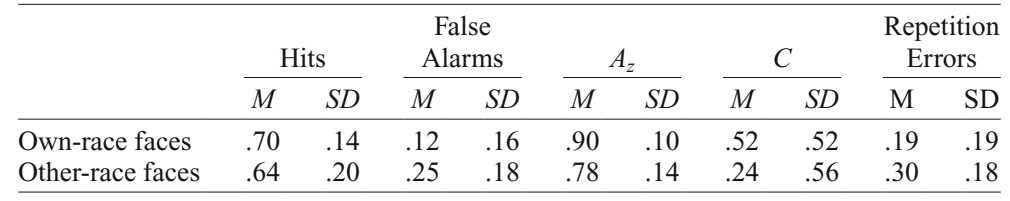

graphs for each face were available: An image of each target face smiling was used at the time of study, whereas another image, in which the target face had a neutral expression, was used at test. All clothing was cropped from the photographs, such that only the face of the target was visible. The experiment was performed on PC computers running Medialab software, with images displayed on 19-in. LCD monitors using a $1,280 \times 1,024$ pixel resolution.

Design and Procedure. A single-factor (race of face: own vs. other race) within-subjects design was employed. The Jennings and Jacoby (1997) repetition lag paradigm was used. The participants viewed a sequence of 30 faces (15 Hispanic and 15 AfricanAmerican) during the study phase and were instructed that they would later be asked to recognize these faces. Faces were presented for $3 \mathrm{sec}$ each at encoding, with a 1-sec interstimulus interval (ISI), and presentation order was randomized for each participant. Immediately following the study phase, the participants completed a 3 -min filler task in which they solved a series of anagrams. During the test phase, the participants were asked to distinguish studied faces from new faces and repetitions of these new faces with intervening lags of 2,5 , and 7 faces. The participants were instructed to respond yes to faces that they had viewed at study and no to new faces and any repetition of a new face that occurred at test. The presentation of old and new faces was randomized for each participant, and the assignment of faces to old and new sets (and to varying lags as new faces) was counterbalanced across participants.

\section{Results and Discussion}

A significant CRE was observed in estimates of hits $[t(53)=2.23, p<.05, d=.35]$, false alarms $[t(53)=5.44$, $p<.001, d=.76]$, discrimination accuracy $[t(53)=$ $5.62, p<.001, d=.73]$, and response criterion $[t(53)=$ 3.93, $p<.001, d=.36$ ]. Consistent with prior research (Meissner \& Brigham, 2001), a mirror effect pattern was observed in which participants produced greater hits and fewer false alarms to own-race faces, resulting in superior discrimination accuracy. Participants were also more liberal in responding to other-race faces. Of particular interest in the present study was the repetition error rate across own- and other-race faces. As predicted, results showed a significant increase in repetition errors for other-race faces $[t(53)=4.04, p<.001, d=.43] .{ }^{1}$ Table 1 presents the means and standard deviations for all measures across own- and other-race faces.

The results of Experiment 1 replicated the robust CRE in face recognition and, furthermore, showed that participants were more likely to commit a repetition error when processing other-race faces. This error may reflect a failure of recollection when recognizing other-race faces, or it could result from greater familiarity-based responding to other-race faces. In Experiment 2, we sought to apply Jennings and Jacoby's (1997) process-dissociation paradigm to the recognition of own- and other-race faces and to directly estimate the contributions of recollection and familiarity.

\section{EXPERIMENT 2}

\section{Method}

Participants. Twenty-two Hispanic undergraduate students $(65 \%$ female, mean age $=19.61$ years) from the University of Texas at El Paso participated in this experiment.

Materials. The facial stimuli chosen for this study included 48 Hispanic and 48 African-American faces. The presentation of stimuli was identical to that employed in Experiment 1.

Design and Procedure. A single-factor (race of target face: own vs. other race) within-subjects design was employed. Once again, the Jennings and Jacoby (1997) repetition lag paradigm was used. Twenty-four faces (12 Hispanic and 12 African-American) were presented in the study phase for a period of $2 \mathrm{sec}$ with a 1-sec ISI. Following the encoding phase, participants solved anagram problems for 3 min before beginning the test phase. In the recognition task, participants completed two phases in which they were asked to exclude and include novel faces that were repeated in the test list. Specifically, during exclude trials, participants were asked to respond yes to old faces, no to new faces when initially presented, and no to any repetition of a new face that occurred at test. During include trials, participants were asked to respond yes to old faces, no to new faces when initially presented, and yes to any repetition of a new face that occurred at test. Lags of 4 and 6 faces separated novel and repeated faces. The presentation of exclusion and inclusion phases was counterbalanced across participants, faces within each phase were randomized across participants, and faces were not repeated across exclusion and inclusion trials.

\section{Results and Discussion}

Recognition performance. A significant CRE was observed in estimates of false alarms $[t(21)=5.96, p<$ $.001, d=1.46]$, discrimination accuracy $[t(21)=8.51$, $p<.001, d=1.39]$, and response criterion $[t(21)=3.26$, $p<.01, d=.52]$. Once again, participants were significantly better at discriminating own-race faces from memory and were more liberal when responding to other-race faces. Table 2 presents the means and standard deviations for all measures across own- and other-race faces.

Table 2

Means and Standard Deviations of Hits, False Alarms, Discrimination Accuracy $\left(A_{z}\right)$, and Response Criterion $(C)$ Across Own- and Other-Race Faces in Experiment 2

\begin{tabular}{|c|c|c|c|c|c|c|c|c|}
\hline & \multicolumn{2}{|c|}{ Hits } & \multicolumn{2}{|c|}{$\begin{array}{c}\text { False } \\
\text { Alarms }\end{array}$} & \multicolumn{2}{|c|}{$A_{z}$} & \multicolumn{2}{|c|}{$C$} \\
\hline & $M$ & $S D$ & $M$ & $S D$ & $M$ & $S D$ & $M$ & $S D$ \\
\hline Own-race faces & .60 & .15 & .09 & .07 & .88 & .08 & .62 & .37 \\
\hline Other-race faces & .54 & .18 & .28 & .18 & .70 & .11 & .30 & .52 \\
\hline
\end{tabular}


Table 3

Means and Standard Deviations of Inclusion, Exclusion, Recollection, and Familiarity Estimates Across Own- and Other-Race Faces in Experiment 2

\begin{tabular}{|c|c|c|c|c|c|c|c|c|}
\hline & \multicolumn{2}{|c|}{ Inclusion } & \multicolumn{2}{|c|}{ Exclusion } & \multicolumn{2}{|c|}{ Recollection } & \multicolumn{2}{|c|}{ Familiarity } \\
\hline & $M$ & $S D$ & $M$ & $S D$ & $M$ & $S D$ & $M$ & $S D$ \\
\hline Ow1 & .78 & .15 & .08 & .09 & .70 & .20 & .29 & .28 \\
\hline Other-race faces & .73 & .13 & .26 & .22 & .45 & .24 & .44 & .26 \\
\hline
\end{tabular}

Recollection- versus familiarity-based processing. Table 3 presents the means and standard deviations associated with the proportion of yes responses to repeated faces in the inclusion (INC) and exclusion (EXC) conditions, as well as estimates of recollection and familiarity across own- and other-race faces. Consistent with Jennings and Jacoby (1997), recollection was computed as $\mathrm{R}=\mathrm{INC}-\mathrm{EXC}$, whereas familiarity was computed as $\mathrm{F}=\mathrm{EXC} /(1-\mathrm{R}) .^{2}$ No significant differences were observed in the inclusion condition $[t(21)=1.23, p=.23$, $d=.24]$; however, consistent with Experiment 1, participants were more likely to commit a repetition error on exclusion trials when viewing other-race faces $[t(21)=4.13$, $p<.001, d=.78]$. Consistent with Meissner, Brigham, and Butz (2005), own-race faces showed significantly greater recollection when compared with other-race faces $[t(21)=4.21, p<.001, d=.83]$, whereas no significant difference in familiarity estimates was observed $[t(21)=$ $1.78, p=.09, d=.38] . .^{3}$

\section{GENERAL DISCUSSION}

The purpose of the present study was to examine the CRE using Jennings and Jacoby's (1997) process-dissociation framework and to assess whether other-race faces were more prone to repetition errors, whereas own-race faces might benefit from recollection-based processing. Prior research using the remember-know-guess paradigm suggested that memory for own-race faces involved greater reliance upon recollection (Meissner, Brigham, \& Butz, 2005); however, the use of phenomenological judgments has been criticized (Dunn, 2004). In the present study, we sought to replicate this finding using a process-dissociation paradigm that did not require such judgments.

In Experiment 1, the results showed the typical CRE findings of greater discrimination accuracy and a more conservative response bias for own-race faces. Additionally, the participants were more likely to falsely recognize repeated other-race faces, thereby committing a repetition error. In Experiment 2, we sought to determine the extent to which recollection and/or familiarity contributed to the superior recognition of own-race faces using processdissociation equations. As predicted, a greater reliance on recollection when processing own-race faces appeared to be responsible for the CRE.

In the present study, we employed only Hispanic participants because of limitations in the participant pool. Meissner, Brigham, and Butz (2005) previously demonstrated similar effects of recollection using the remember-know-guess paradigm with Caucasian and African-American samples, whereas the present study demonstrated the influence of recollection with a Hispanic sample. Although we have no reason to believe that these results would not generalize to other racial or ethnic groups, further research demonstrating the generality of recollection-based processes in accounting for the CRE would prove useful.

The influence of recollection within the CRE suggests that own-race faces may be encoded using greater attentional resources and may be represented in memory with respect to more diagnostic feature sets, leading to superior recognition. Although this is consistent with several theories accounting for the CRE (Chiroro \& Valentine, 1995; Sporer, 2001; Valentine, 1991, 2001), a processdissociation perspective allows us to further make predictions regarding conditions under which the CRE might be mitigated. For example, situations that disrupt effortful or semantic encoding or that distract participants' attention at study or recognition should lead to a lessening of the CRE by reducing performance on own-race faces. Along similar lines, manipulations that improve encoding may not differentially improve performance on otherrace faces. For example, own-race faces appear to benefit most from those factors that promote the use of contextual information - a finding confirmed in two recent studies (Evans, Marcon, \& Meissner, in press; Horry \& Wright, 2008). In contrast, participants' criterion of responding is unlikely to fully account for the CRE, since manipulations that influence response bias are typically associated with differences in reported familiarity (see Yonelinas, 2002). In the present study, it is likely that the CRE observed in a measure of response criterion was associated with the greater (though nonsignificant) familiarity estimates observed in the recognition of other-race faces.

From a practical perspective, a recollection-based interpretation of the CRE would suggest a difficulty in moderating the effect at the time of a lineup identification. For example, some studies have suggested that sequential presentation of faces may lead witnesses to provide more conservative responses (Meissner, Tredoux, Parker, \& MacLin, 2005). Although such a manipulation may moderate participants' liberal responding to other-race faces, it is unlikely to lead to better discrimination (or promote greater recollection). As noted above, attempts at providing context reinstatement support similarly fail to improve performance on other-race faces (Evans et al., in press). Future research assessing predictions regarding the role of recollection in the CRE would appear warranted.

\section{AUTHOR NOTE}

This research was supported by National Science Foundation Grant SES-0611636 to the third author. Any opinions, findings, and conclusions 
or recommendations expressed in this material are those of the authors and do not necessarily reflect the views of the National Science Foundation. Correspondence concerning this article should be addressed to C. A. Meissner, Department of Psychology, University of Texas at El Paso, El Paso, TX 79968 (e-mail: cmeissner@utep.edu).

\section{REFERENCES}

Bodner, G. E., \& LindsaY, D. S. (2003). Remembering and knowing in context. Journal of Memory \& Language, 48, 563-580

Brigham, J. C., \& Malpass, R. S. (1985). The role of experience and contact in the recognition of own- and other-race persons. Journal of Social Issues, 41, 139-155.

Chiroro, P. M., Tredoux, C. G., Radaelli, S., \& Meissner, C. A. (2008). Recognizing faces across continents: The effect of within-race variations on the own-race bias in face recognition. Psychonomic Bulletin \& Review, 15, 1089-1092.

Chiroro, P. M., \& VAlentine, T. (1995). An investigation of the contact hypothesis of the own-race bias in face recognition. Quarterly Journal of Experimental Psychology, 48A, 879-894.

Dasgupta, N., McGhee, D. E., Greenwald, A. G., \& Banaji, M. R. (2000). Automatic preference for White Americans: Eliminating the familiarity explanation. Journal of Experimental Social Psychology, 36, 316-328.

Dunn, J. C. (2004). Remember-know: A matter of confidence. Psychological Review, 111, 524-542.

Evans, J. R., Marcon, J. L., \& Meissner, C. A. (in press). Cross-racial lineup identification: The potential benefits of context reinstatement. Psychology, Crime, \& Law.

Gardiner, J. M., \& Richardson-KLAVEhn, A. (2000). Remembering and knowing. In E. Tulving \& F. I. M. Craik (Eds.), The Oxford handbook of memory (pp. 229-244). New York: Oxford University Press.

Horry, R., \& Wright, D. B. (2008). I know your face but not where I saw you: Context memory is impaired for other-race faces. Psychonomic Bulletin \& Review, 15, 610-614.

JACOBY, L. L. (1991). A process dissociation framework: Separating automatic from intentional uses of memory. Journal of Memory \& Language, 30, 513-541

JENNINGS, J. M., \& JACOBY, L. L. (1997). An opposition procedure for detecting age-related deficits in recollection: Telling effects of repetition. Psychology \& Aging, 12, 352-361.

Kelley, C. M., \& JaCoBy, L. L. (2000). Recollection and familiarity: Process-dissociation. In E. Tulving \& F. I. M. Craik (Eds.), The Oxford handbook of memory (pp. 215-228). New York: Oxford University Press.

LEvin, D. T. (1996). Classifying faces by race: The structure of face categories. Journal of Experimental Psychology: Learning, Memory, \& Cognition, 22, 1364-1382.

LEvin, D. T. (2000). Race as a visual feature: Using visual search and perceptual discrimination tasks to understand face categories and the cross-race recognition deficit. Journal of Experimental Psychology, 129, 559-574.

MacLin, O. H., \& Malpass, R. S. (2001). Racial categorization of faces: The ambiguous race face effect. Psychology, Public Policy, \& Law, 7, 98-118.

Malpass, R. S., \& Kravitz, J. (1969). Recognition for faces of own and other race. Journal of Personality \& Social Psychology, 13, 330-334.

Meissner, C. A., \& Brigham, J. C. (2001). Thirty years of investigating the own-race bias in memory for faces: A meta-analytic review. Psychology, Public Policy, \& Law, 7, 3-35.

Meissner, C. A., Brigham, J. C., \& Butz, D. A. (2005). Memory for own- and other-race faces: A dual-process approach. Applied Cognitive Psychology, 19, 545-567.
Meissner, C. A., Tredoux, C. G., Parker, J. F., \& Maclin, O. H. (2005). Eyewitness decisions in simultaneous and sequential lineups: A dual-process signal detection theory analysis. Memory \& Cognition, 33, 783-792.

Payne, B. K., Lambert, A. J., \& Jacoby, L. L. (2002). Best laid plans: Effects of goals on accessibility bias and cognitive control in racebased misperceptions of weapons. Journal of Experimental Social Psychology, 38, 384-396.

Rhodes, G., Hayward, W. G., \& Winkler, C. (2006). Expert face coding: Configural and component coding of own-race and other-race faces. Psychonomic Bulletin \& Review, 13, 499-505.

Rhodes, G., Tan, S., Brake, S., \& TAYLOR, K. (1989). Expertise and configural coding in face recognition. British Journal of Psychology, 80, 313-331

SPORER, S. L. (2001). The cross-race effect: Beyond recognition of faces in the laboratory. Psychology, Public Policy, \& Law, 7, 170-200.

Tulving, E. (1985). Memory and consciousness. Canadian Psychology, 26, 1-12.

VALENTine, T. (1991). A unified account of the effects of distinctiveness, inversion, and race in face recognition. Quarterly Journal of Experimental Psychology, 43A, 161-204.

VALENTINe, T. (2001). Face-space models of face recognition. In M. J. Wenger \& J. T. Townsend (Eds.), Computational, geometric, and process perspectives on facial cognition: Contexts and challenges (pp. 83-113). Hillsdale, NJ: Erlbaum.

Wright, D. B., Boyd, C. E., \& Tredoux, C. G. (2003). Inter-racial contact and the own-race bias for face recognition in South Africa and England. Applied Cognitive Psychology, 17, 365-373.

YoNeLINAS, A. P. (1994). Receiver-operating characteristics in recognition memory: Evidence for a dual-process model. Journal of Experimental Psychology: Learning, Memory, \& Cognition, 20, 13411354.

YoNELINAS, A. P. (1999). The contribution of recollection and familiarity to recognition and source memory: An analysis of receiver-operating characteristics and a formal model. Journal of Experimental Psychology: Learning, Memory, \& Cognition, 25, 1415-1434.

Yonelinas, A. P. (2001). Consciousness, control, and confidence: The 3 Cs of recognition memory. Journal of Experimental Psychology: General, 130, 361-379.

Yonelinas, A. P. (2002). The nature of recollection and familiarity: A review of 30 years of research. Journal of Memory \& Language, 46, 441-517.

Yonelinas, A. P., Kroll, N. E. A., Dobbins, I. G., \& Soltani, M. (1999). Recognition memory for faces: When familiarity supports associative recognition judgments. Psychonomic Bulletin \& Review, 6, 654-661.

\section{NOTES}

1. Repetition errors increased in a linear fashion across lags of 2, 5, and $7\left[F(1,53)=4.42, p<.05, \eta^{2}=.08\right]$; however, lag failed to interact with the $\operatorname{CRE}\left[F(1,53)=0.34\right.$, n.s., $\left.\eta^{2}=.01\right]$.

2 . The interested reader can obtain a complete description and derivation of these formulae from Jennings and Jacoby (1997, p. 356).

3. Repetition errors did not significantly differ as a function of lag $\left[F(1,19)=0.05\right.$, n.s., $\left.\eta^{2}=.003\right]$, and lag failed to interact with the CRE $\left[F(1,19)=0.59\right.$, n.s., $\left.\eta^{2}=.03\right]$.

(Manuscript received May 15, 2008; revision accepted for publication July 22, 2008.) 